\title{
The anionic ring-opening polymerization of five-membered cyclic carbonates fused to the cyclohexane ring
}

\author{
Kunio Tezuka, Kazuhito Komatsu and Osamu Haba
}

The anionic polymerization of five-membered cyclic carbonates fused to a cyclohexane ring, that is, the trans- and cis-cyclohexane-1,2-diyl carbonates (trans- and cis-1, respectively), were examined as a model polymerization example to reveal the origin of the unusually good polymerizability of the previously reported methyl 4,6-O-benzylidene-2,3-0-carbonyl- $\alpha$, D-glucopyranoside. The tert-BuOK-initiated anionic polymerization of trans-1 produces polymers with $M_{\mathrm{n}}$ values of 11000 , whereas no polymeric products were obtained from cis-1. The structure of the poly(trans-1) was confirmed by comparison with the model carbonate (2) based on the ${ }^{13} \mathrm{C}$ NMR spectra as well as the hydrolysis experiments. The poly(trans-1) form essentially consists of polycarbonate units; therefore, the polymerization of trans- 1 was not accompanied by any decarboxylation. The thermodynamic parameters for the polymerization of trans-1 were estimated to be $\Delta H_{\mathrm{p}}^{\circ}=-23 \mathrm{~kJ} \mathrm{~mol}-1$ and $\Delta S_{\mathrm{p}}^{\circ}=-63 \mathrm{~J} \mathrm{~K}^{-1} \mathrm{~mol}^{-1}$.

Polymer Journal (2013) 45, 1183-1187; doi:10.1038/pj.2013.50; published online 29 May 2013

Keywords: aliphatic polycarbonate; anionic polymerization; ring-opening polymerization; thermodynamic

\section{INTRODUCTION}

Aliphatic polycarbonates are biocompatible and biodegradable materials. ${ }^{1-3}$ For their synthesis, various procedures have been used, that is, (i) the polycondensation between the carbonate derivatives and diols, ${ }^{4}$ (ii) the ring-opening polymerization of cyclic carbonates, ${ }^{5-19}$ and (iii) the alternating polymerization of epoxides with carbon dioxide. Among these procedures, the ring-opening polymerizations of cyclic carbonates have the potential to control the molecular weight and to induce copolymerization with other cyclic monomers.

The anionic ring-opening behavior of the cyclic carbonates is known to depend on the ring size. Six-membered cycles (or larger) using anionic initiators tend to polymerize smoothly, yielding the corresponding polycarbonate at a lower temperature $\left(<100^{\circ} \mathrm{C}\right) .{ }^{5-19}$ In contrast, the anionic ring-opening polymerization of the fivemembered ring is thermodynamically unfavorable and proceeds at a higher temperature $\left(>150^{\circ} \mathrm{C}\right)$, causing the elimination of carbon dioxide to produce a copolymer that consists of both carbonate and ether linkages. ${ }^{20-25}$ However, we reported that the anionic ringopening polymerization of a five-membered cyclic carbonate (MBCG) (Figure 1) possessing the $\alpha, \mathrm{D}$-glucopyranoside structure proceeded even at $0^{\circ} \mathrm{C}$ to produce an aliphatic polycarbonate without the elimination of carbon dioxide.

Additionally, MBCG was found to have corresponding polymerizability to L-lactide (LL), because the copolymerization of MBCG with LL almost produces random copolymers. We attributed the high polymerization tendency of MBCG to the ring strain of the five-membered carbonate ring, which is attached to the pyranoside ring in the trans fashion.

To confirm the high polymerizability of the trans-fused cyclic carbonate, we examined the anionic ring-opening polymerization of the model compounds, that is, the trans- and cis-cyclohexane-1,2-diyl carbonates (trans- and cis-1, respectively) (Figure 1). In this study, we report the anionic polymerization behavior of trans- and cis-1 and compare their polymerization abilities.

\section{EXPERIMENTAL PROCEDURE}

\section{Measurements}

${ }^{1} \mathrm{H}$ and ${ }^{13} \mathrm{C}$ NMR spectra were measured in $\mathrm{CDCl}_{3}$ or $\mathrm{C}_{6} \mathrm{D}_{6}$ using a JEOL JNMECX 400 spectrometer (JEOL, Tokyo, Japan; $400 \mathrm{MHz}$ for ${ }^{1} \mathrm{H}$ and $100 \mathrm{MHz}$ for ${ }^{13} \mathrm{C}$ ) at room temperature. The chemical shift values were recorded in p.p.m. downfield from tetramethylsilane (0.0 p.p.m.) and $\mathrm{CDCl}_{3}$ (77.0 p.p.m.) or $\mathrm{C}_{6} \mathrm{D}_{6}$ (128.0 p.p.m.), which were used as the internal standard for the ${ }^{1} \mathrm{H}$ and ${ }^{13} \mathrm{C}$ measurements, respectively. The number-average $\left(M_{\mathrm{n}}\right)$ and weight-average $\left(M_{\mathrm{w}}\right)$ molecular weights were estimated by size-exclusion chromatography (SEC) using a Tosoh DP-8020 pump (Tosoh, Tokyo, Japan), a Viscotek TDA MODEL-300 refractive index detector and polystyrene gel columns (Tosoh, TSK gels G2500H, G3000H, G4000H and GMH) in THF or chloroform.

\section{Materials}

Tetrahydrofuran (THF, Kanto Chemicals, Akishima, Japan) was refluxed over sodium-benzophenone ketyl and was distilled immediately prior to use. 


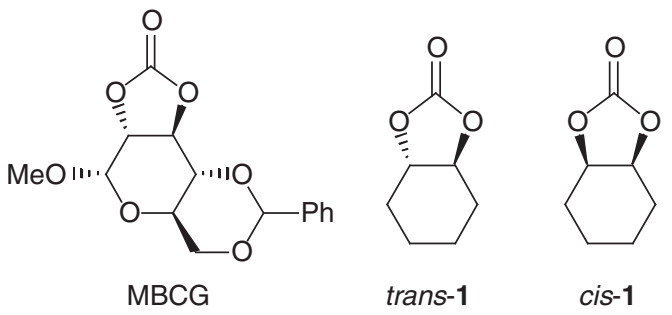

Figure 1 The structures of MBCG, trans-1 and cis-1.

Potassium tert-butoxide $\left({ }^{t} \mathrm{BuOK}\right)$ was purchased as a $1.0 \mathrm{M}$ solution in THF (Aldrich, Tokyo, Japan) and was used as received. The trans- and cis-cyclohexane-1,2-diols were prepared from cyclohexene according to the literature. $^{26,27}$ All other chemicals were commercially available and used as received.

\begin{abstract}
Monomer synthesis
trans-Cyclohexane-1,2-diyl carbonate (trans-1). Ethyl chloroformate $(240 \mathrm{ml}$, $2.52 \mathrm{~mol}$ ) was added drop-wise at $5{ }^{\circ} \mathrm{C}$ to a solution of trans-cyclohexane-1,2diol $(10 \mathrm{~g}, 86 \mathrm{mmol})$ in 1,4-dioxane $(120 \mathrm{ml})$. A solution of triethylamine $(85 \mathrm{ml}, 0.61 \mathrm{~mol})$ in toluene $(400 \mathrm{ml})$ was then slowly added so that the temperature of the solution did not exceed $20^{\circ} \mathrm{C}$. The resulting white suspension was further stirred for $1 \mathrm{~h}$ at $5^{\circ} \mathrm{C}$. Filtration was used to remove the formed salt, and the filtrate was washed with $1 \mathrm{wt} \%$ aqueous hydrochloric acid until acidified, and then with water to neutralize. The organic layer was dried over $\mathrm{MgSO}_{4}$ and was concentrated under reduced pressure. The residue was recrystallized from $\mathrm{n}$-hexane to give colorless needles. Yield $7.1 \mathrm{~g}$ (50 mmol, 58\%). MP $57-58{ }^{\circ} \mathrm{C}$ (lit. 53-54 ${ }^{\circ} \mathrm{C}$ ). ${ }^{28,29}{ }^{1} \mathrm{H}$ NMR $(400 \mathrm{MHz}$, $\left.\mathrm{CDCl}_{3}\right): \delta$ (p.p.m.) $=4.14-3.97(\mathrm{~m}, 2 \mathrm{H}, \mathrm{CH}), 2.39-2.13(\mathrm{~m}, 2 \mathrm{H}$, equatorial $\mathrm{H}-3$ and $\mathrm{H}-6), 2.07-1.82(\mathrm{~m}, 2 \mathrm{H}$, axial $\mathrm{H}-3$ and $\mathrm{H}-6), 1.81-1.52(\mathrm{~m}, 2 \mathrm{H}$, axial $\mathrm{H}-4$ and $\mathrm{H}-5), 1.52-1.23(\mathrm{~m}, 2 \mathrm{H}$, equatorial $\mathrm{H}-4$ and $\mathrm{H}-5) .{ }^{13} \mathrm{C}$ NMR $\left(100 \mathrm{MHz}, \mathrm{CDCl}_{3}\right): \delta$ (p.p.m.) $=155.1(\mathrm{C}=\mathrm{O}), 83.5(\mathrm{CH}), 28.2(\mathrm{C}-3$ and C-6), 23.2 (C-4 and C-5).
\end{abstract}

cis-Cyclohexane-1,2-diyl carbonate (cis-1). Cis-1 was prepared from ciscyclohexane-1,2-diol $(2.0 \mathrm{~g}, 17 \mathrm{mmol}$ ) according to a procedure that was similar to that used for the trans-1. Pure cis-1 was obtained as colorless needles after recrystallization from ethyl acetate-petroleum ether. Yield $1.5 \mathrm{~g}$ (11 mmol, 61\%). MP 40-41 ${ }^{\circ} \mathrm{C}$ (lit. $\left.35-37^{\circ} \mathrm{C}\right) .{ }^{30} \mathrm{H}$ NMR ( $400 \mathrm{MHz}, \mathrm{CDCl}_{3}$ ): $\delta$ (p.p.m. $)=4.74-4.67(\mathrm{~m}, 2 \mathrm{H}, \mathrm{CH}), 1.91-1.87\left(\mathrm{~m}, 4 \mathrm{H}, \mathrm{CH}_{2}\right), 1.70-1.36$ $\left(\mathrm{m}, 4 \mathrm{H}, \mathrm{CH}_{2}\right) .{ }^{13} \mathrm{C} \mathrm{NMR}\left(100 \mathrm{MHz}, \mathrm{CDCl}_{3}\right): \delta$ (p.p.m. $)=155.4(\mathrm{C}=\mathrm{O}), 75.7$ $(\mathrm{CH}), 26.5$ (C-3 and C-6), 18.9 (C-4 and C-5).

\section{Polymerization}

The following describes a typical polymerization procedure. In a test tube equipped with a three-way stopcock and filled with nitrogen, trans-1 $(0.57 \mathrm{~g}$, $4.0 \mathrm{mmol})$ was melted at $60^{\circ} \mathrm{C}$ using an oil bath. An initiator, ${ }^{t} \mathrm{BuOK}(1.0 \mathrm{M}$ solution in THF, $0.16 \mathrm{ml}, 0.16 \mathrm{mmol}$ ) was added via syringe. The mixture was stirred at this temperature for $3 \mathrm{~h}$. Acetic acid $(12 \mu \mathrm{l})$ was added to quench the reaction, and the solution was then poured into petroleum ether $(50 \mathrm{ml})$. The white precipitate was collected by filtration, reprecipitated from $\mathrm{CHCl}_{3}-$ petroleum ether and dried in vacuo at room temperature. Yield $0.49 \mathrm{~g}$ $(83 \%) . M_{\mathrm{n}}=11000$ (SEC). $M_{\mathrm{w}} / M_{\mathrm{n}}=3.9$.

\section{Model compound}

trans-1,2-bis(ethoxycarbonyloxy)cyclohexane (2). 2 was prepared from transcyclohexane-1,2-diol (1.3 g, $11 \mathrm{mmol})$ according to the literature. ${ }^{31}$ Pure 2 was obtained as a white solid after performing column chromatography on silica gel with ethyl acetate/n-hexane $(1 / 1, v / v)$. Yield, $1.1 \mathrm{~g}(4.3 \mathrm{mmol}, 39 \%)$. ${ }^{1} \mathrm{H}$ NMR $\left(400 \mathrm{MHz}, \mathrm{C}_{6} \mathrm{D}_{6}\right): \delta$ (p.p.m. $)=4.89-4.79(\mathrm{~m}, 2 \mathrm{H}, \mathrm{CH}), 4.04-3.82$ (m, 2H, $\left.\mathrm{OCH}_{2}\right), 2.08-1.92\left(\mathrm{~m}, 2 \mathrm{H}, \mathrm{CH}_{2}\right), 1.36-1.12\left(\mathrm{~m}, 4 \mathrm{H}, \mathrm{CH}_{2}\right), 1.00-0.80$ $\left(\mathrm{m}, 8 \mathrm{H}, \mathrm{CH}_{3}\right.$ and $\left.\mathrm{CH}_{2}\right) .{ }^{13} \mathrm{C}$ NMR $\left(100 \mathrm{MHz}, \mathrm{C}_{6} \mathrm{D}_{6}\right): \delta$ (p.p.m. $)=155.0$ $(\mathrm{C}=\mathrm{O}), 77.0(\mathrm{CH}), 63.7\left(\mathrm{OCH}_{2}\right), 30.0(\mathrm{C}-3$ and $\mathrm{C}-6), 23.1(\mathrm{C}-4$ and $\mathrm{C}-5)$, $14.1\left(\mathrm{CH}_{3}\right)$.
Table 1 The anionic polymerization of trans- and cis-1 with ${ }^{t}$ BuOK. $^{\mathrm{a}}$

\begin{tabular}{|c|c|c|c|c|c|c|c|}
\hline Run & Monomer & Solvent & {$[\mathrm{M}]_{0}\left(\mathrm{moll}^{-1}\right)$} & Temp $\left({ }^{\circ} \mathrm{C}\right)$ & Yield $^{\mathrm{b}},(\%)$ & $M_{\mathrm{n}} 10^{-3 \mathrm{c}}$ & $M_{\mathrm{w}} / M_{\mathrm{n}}{ }^{\mathrm{c}}$ \\
\hline 1 & trans-1 & Diglyme & 5.0 & 150 & 0 & - & - \\
\hline 2 & trans-1 & Diglyme & 5.0 & 60 & 0 & - & - \\
\hline 3 & trans-1 & THF & 5.0 & 60 & 44 & 0.4 & 1.0 \\
\hline 4 & trans-1 & None & - & 150 & 35 & 4.3 & 1.4 \\
\hline 5 & trans-1 & None & - & 60 & 69 & 11.0 & 3.9 \\
\hline 6 & cis-1 & Diglyme & 5.0 & 150 & 0 & - & - \\
\hline 7 & cis-1 & Diglyme & 5.0 & 60 & 0 & - & - \\
\hline 8 & cis-1 & THF & 5.0 & 60 & 0 & - & - \\
\hline 9 & cis-1 & None & - & 150 & 0 & - & - \\
\hline 10 & cis-1 & None & - & 60 & 0 & - & - \\
\hline
\end{tabular}

${ }^{a}[\mathrm{M}]_{0} /[\mathrm{I}]_{0}=25$, Time; $3 \mathrm{~h}$.

Petroleum-ether-insoluble fraction.

'Estimated by SEC eluted in THF with polystyrene standard.

\section{RESULTS AND DISCUSSION}

\section{Monomer synthesis}

For the monomer synthesis, the corresponding diols were prepared according to the literature. Trans-cyclohexane-1,2-diol was synthesized by the oxidation of cyclohexene with $\mathrm{H}_{2} \mathrm{O}_{2}$ aq, followed by alkaline hydrolysis. ${ }^{26}$ Cis-cyclohexane-1,2-diol was synthesized by the oxidation of cyclohexene with osmium tetroxide in the presence of $\mathrm{N}$-methylmorpholine $\mathrm{N}$-oxide. ${ }^{27}$ Trans- and cis-1 were synthesized from ethyl chloroformate and the corresponding diols. The structures of the monomers were confirmed by ${ }^{1} \mathrm{H}$ and ${ }^{13} \mathrm{C}$ NMR.

\section{Polymerization}

Table 1 shows the polymerization results of the trans- and cis-1. The polymerizations were carried out using ${ }^{t} \mathrm{BuOK}$ as the initiator, which is a very common anionic initiator for lactones, including cyclic carbonates. The solution polymerizations of trans-1 were carried out in bis(2-methoxyethyl) ether (diglyme) or tetrahydrofuran (THF) (runs 1, 2 and 3). The polymerization in diglyme gave no polymeric material at either 60 or $150^{\circ} \mathrm{C}$ (runs 1 and 2), whereas polymerization in THF produced the petroleum-ether-insoluble material at $44 \%$ yield. The products, however, showed only low number-average molecular weights $\left(M_{n}\right)$ of 400 ; therefore, the solution polymerization of trans-1 hardly proceeded. However, the melt polymerization without solvents produced a polymeric product that was insoluble in petroleum ether (runs 3-5) and exhibited a relatively higher $M_{\mathrm{n}}$ of 11000 at $60^{\circ} \mathrm{C}$ (run 5). The $M_{\mathrm{n}}$ tended to decrease with increasing polymerization temperature (run 4). Such a tendency is often seen during equilibrium polymerizations, that is, a lower monomer concentration and higher temperature lead to suppression of the polymerization progress. The polydispersity index (PDI, $\left.M_{\mathrm{w}} / M_{\mathrm{n}}\right)$ at $150^{\circ} \mathrm{C}$ was 1.4 , which was also lower than at $60^{\circ} \mathrm{C}$, despite the common tendency of equilibrium polymerization to become large at higher temperature. It is likely that the polymeric products at $150{ }^{\circ} \mathrm{C}$ had a low $M_{\mathrm{n}}$ and significantly dissolved in the petroleum ether during reprecipitation, causing the PDI at $150{ }^{\circ} \mathrm{C}$ to be smaller than the actual value. However, the polymerization of cis-1 gave no polymeric products under any conditions (runs 6-10).

To examine the influence of time on the polymerization of 1 , the polymerization was carried out from $1 \mathrm{~h}$ to $24 \mathrm{~h}$. Figure 2 shows the relationship between the polymerization time and the yield of trans-1 at $60^{\circ} \mathrm{C}$ and $150^{\circ} \mathrm{C}$. At $60^{\circ} \mathrm{C}$, the yield and $M_{\mathrm{n}}$ increased until $12 \mathrm{~h}$, after which time both values slightly decreased. At $150^{\circ} \mathrm{C}$, the yield 
and $M_{\mathrm{n}}$ tended to decrease with increasing polymerization time. The ${ }^{13} \mathrm{C}$ NMR spectrum of the filtrate of poly $($ trans -1$)$ at $150{ }^{\circ} \mathrm{C}$ is analogous to poly(cyclohexene oxide) and showed no carbonyl carbon signal. This means that at $150^{\circ} \mathrm{C}$, the polycarbonate units were decarboxylated to produce oligoether units, and the $M_{\mathrm{n}}$ decreased. However, the polymerization of cis-1 gave no polymeric products even if the polymerization time was extended.

\section{Polymer structure}

As already mentioned, it is well known that the ring-opening polymerizations of cyclic carbonates are accompanied by decarboxylation to produce the polyether repeating unit. To clarify the structure of the obtained polymer, trans-1,2-bis(ethoxycarbonyloxy)cyclohexane (2) was prepared as a model compound for the carbonate repeating units. Figure 3 shows the ${ }^{13} \mathrm{C}$ NMR spectra of the obtained polymer (run 5 in Table 1) and model compound (2). The ${ }^{13} \mathrm{C}$ NMR spectra of the obtained polymer showed sharp signals at 154.6 p.p.m.. These data agreed with that of 2 at 155.0 p.p.m., which was assigned to the carbonyl carbon. Additionally, the signals at 77.7, 30.0 and 23.0 p.p.m. in the polymer spectrum were comparable

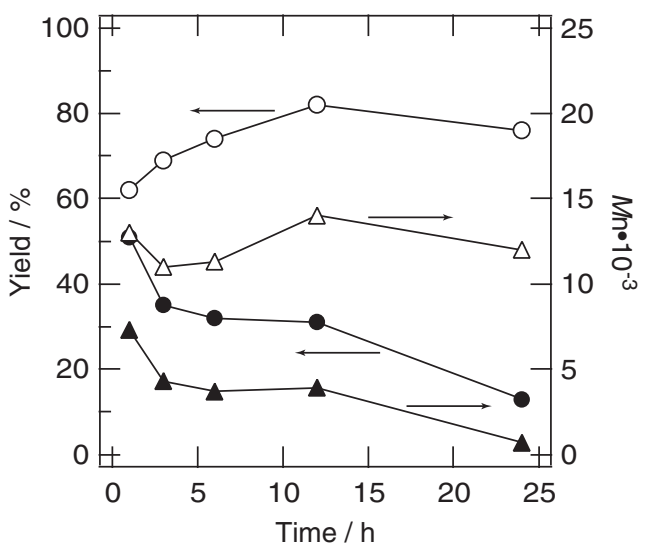

Figure 2 The yield and $M_{\mathrm{n}}$ as a function of time for the bulk polymerization of trans-1. initiated by ${ }^{t} \mathrm{BuOK}$. $[\mathrm{M}]_{0} /[\mathrm{I}]_{0}=25$. (O) $(\Delta)=60^{\circ} \mathrm{C}$, $(\mathbf{\Delta})=150^{\circ} \mathrm{C}$.
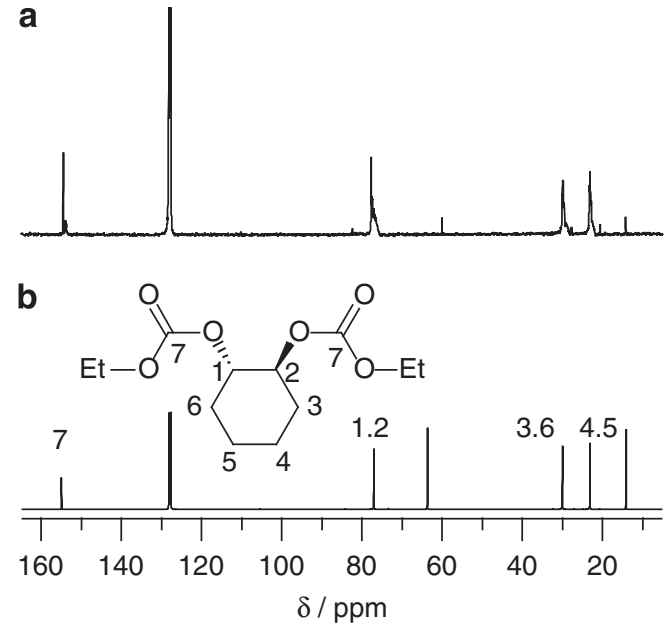

Figure $3{ }^{13} \mathrm{C}$ NMR spectra of (a) the obtained polymer (run 5 in Table 1) and (b) 2 measured in $\mathrm{C}_{6} \mathrm{D}_{6}$. to the methyne carbon, which appeared at 77.0, and the methylene carbons, which appeared at 30.0 and 23.1 p.p.m. of 2. Thus, the spectrum of the obtained polymer agreed well with that of 2 . This implies that the polymerizations of trans-1 proceeded without decarboxylation.

To further confirm that the anionic polymerizations of trans-1 proceed without decarboxylation, the alkaline hydrolysis of the poly(trans-1) was carried out. If carbon dioxide elimination occurred during the anionic polymerization of trans-1, the resulting polymer should contain polyether repeating units, which should be inert to hydrolysis. The polycarbonate repeating units are likely hydrolyzed to give the trans-cyclohexane-1,2-diol. Figure 4 shows the SEC chromatograms of the original polymer, the hydrolysis product, and trans-cyclohexane-1,2-diol as a model compound. The peak due to the higher molecular weight in the polymer chromatogram was completely absent in that of the hydrolysis product, which instead showed a sharp peak at a lower weight, corresponding to that of trans-cyclohexane-1,2-diol.

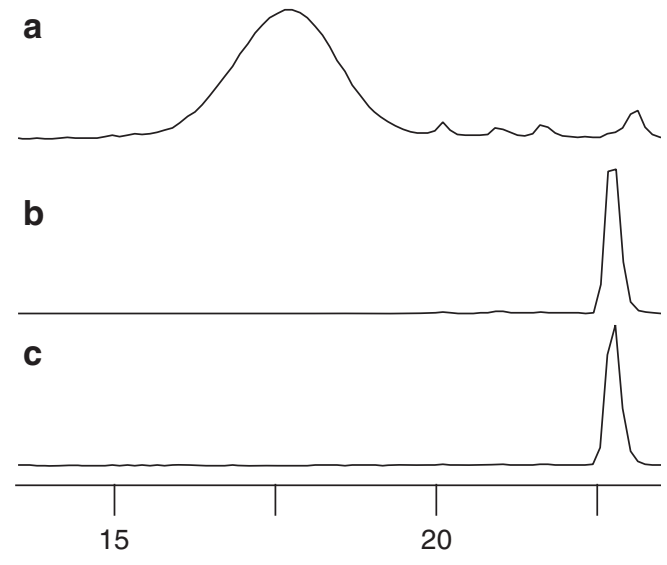

Elution volume / $\mathrm{mL}$

Figure 4 SEC chromatograms of (a) the original polymer (run 5 in Table 1), (b) their hydrolyzate, and (c) trans-cyclohexane-1,2-diol eluted with chloroform. The hydrolysis was carried out using $\mathrm{KOH}$ in ethanol at room temperature for $3 \mathrm{~h}$.

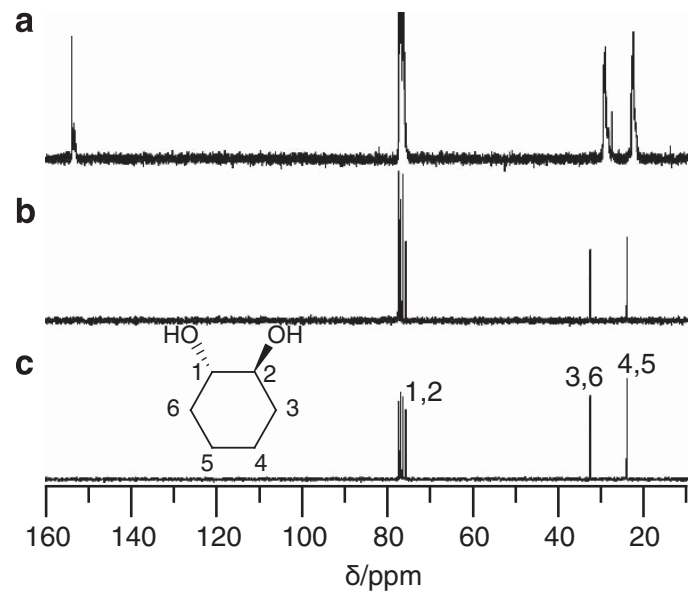

Figure $5{ }^{13} \mathrm{C}$ NMR spectra of (a) the original polymer (run 5 in Table 1), (b) their hydrolyzates, and (c) trans-cyclohexane-1,2-diol measured in $\mathrm{CDCl}_{3}$. 


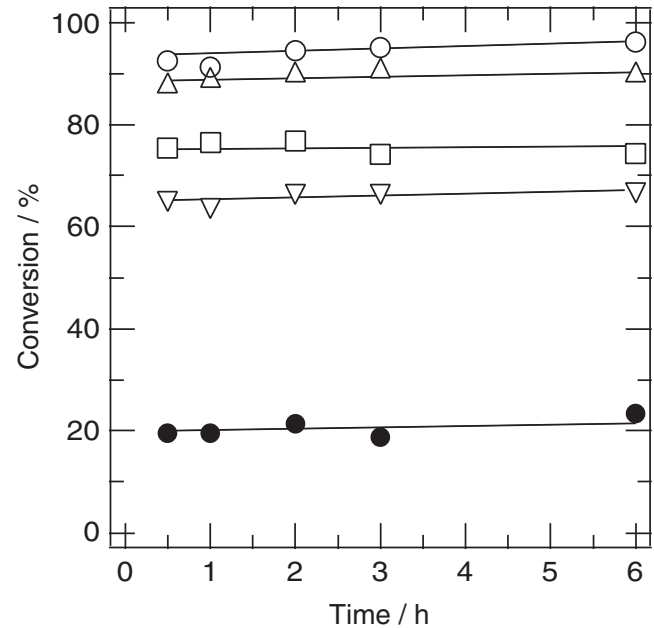

Figure 6 Monomer conversion as a function of the reaction time for the solution. polymerization of trans-1 with ${ }^{t} \mathrm{BuOK}$. Solvent: THF, $[\mathrm{M}]_{0}=0.1 \mathrm{~mol} / \mathrm{l}, \quad[\mathrm{M}]_{0} /[\mathrm{I}]_{0} \quad=25 . \quad(O)=-60^{\circ} \mathrm{C}, \quad(\Delta)=-40^{\circ} \mathrm{C}$, $(\square)=-20^{\circ} \mathrm{C},(\nabla)=0^{\circ} \mathrm{C},(\bullet)=30^{\circ} \mathrm{C}$.

Figure 5 shows the ${ }^{13} \mathrm{C}$ NMR spectra of the original polymer (run 5 in Table 1), the hydrolysis product, and trans-cyclohexane-1,2-diol. The peak at 153.8 p.p.m. was derived from the carbonate units and completely disappeared after hydrolysis, and the spectra of the hydrolysis product and trans-cyclohexane-1,2-diol completely agreed each other over the entire spectral range. These results indicate that hydrolysis proceeded to completion and that the hydrolysis product did not contain polyether units, that is, the anionic polymerization of trans-1 proceeded without decarboxylation, and the obtained polymer consisted of only polycarbonate units.

\section{Thermodynamics}

The polymerizability of cyclic monomers is strongly related to the enthalpy change $\left(\Delta H_{\mathrm{p}}{ }^{\circ}\right)$ and entropy change $\left(\Delta S_{\mathrm{p}}{ }^{\circ}\right)$ of the ringopening process. The equilibrium monomer concentration $\left([\mathrm{M}]_{\mathrm{e}}\right)$ is related to the enthalpy and entropy of polymerization (Equation (1)). ${ }^{32}$

$$
\ln \left(\frac{\mathrm{DP}_{n}}{\mathrm{DP}_{n}-1}[\mathrm{M}]_{\mathrm{e}}\right)=\frac{\Delta H_{\mathrm{p}}^{\circ}}{\mathrm{R} T}-\frac{\Delta S_{\mathrm{P}}^{\circ}}{\mathrm{R}}
$$

$[\mathrm{M}]_{\mathrm{e}}$ can be calculated based on the monomer conversion at equilibrium. However, we could not obtain $[\mathrm{M}]_{\mathrm{e}}$ for the melt polymerizations, because the monomer conversions reached $\sim 100 \%$ within $1 \mathrm{~h}$ at high temperature. Therefore, the polymerizations were carried out in a dilute $(0.1 \mathrm{M})$ solution. The monomer conversions were calculated using the area ratio of the signals of the methyne proton of trans-1 and poly(trans-1), which appeared at 4.06 and 4.65 p.p.m., respectively, in the ${ }^{1} \mathrm{H}$ NMR spectra. The $\mathrm{DP}_{n}$ s were also estimated from the ${ }^{1} \mathrm{H}$ NMR spectra using the methyne protons of the repeating and terminal units. Figure 6 shows the plotted monomer conversion versus the polymerization time during the solution polymerization at polymerization temperatures ranging from $-60{ }^{\circ} \mathrm{C}$ to $30^{\circ} \mathrm{C}$. The monomer conversion reached a constant value immediately after initiation. With respect to the period after the constant conversions, where the polymerization was in equilibrium, the $[\mathrm{M}]_{\mathrm{e}}$ values were calculated from the conversions. According to Equation (1), the $\ln \left(\left(\mathrm{DP}_{n} \cdot[\mathrm{M}]_{\mathrm{e}}\right) /\left(\mathrm{DP}_{n}-1\right)\right)$, the calculated and obtained $[\mathrm{M}]_{\mathrm{e}}$ and $\mathrm{DP}_{n}$ values were plotted versus $T^{-1}$ in Figure 7.

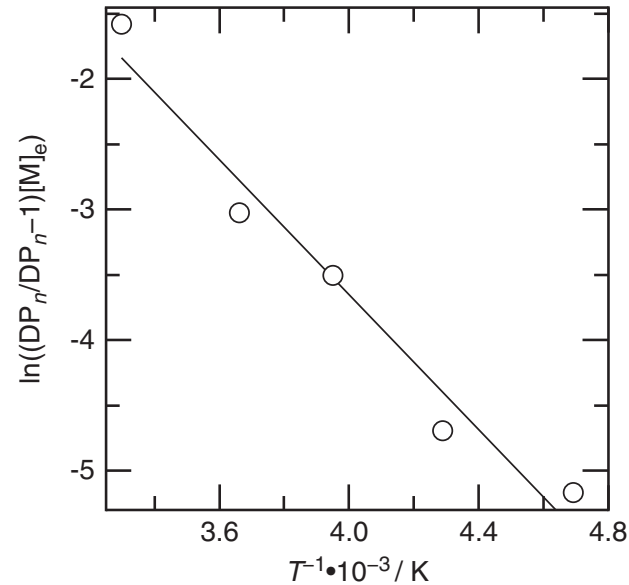

Figure 7 Dainton's plot for the anionic solution polymerization of trans-1.

Table $2 \Delta H p^{\circ}$ and $\Delta S p^{\circ}$ of the ring-opening polymerization of cyclic carbonates

\begin{tabular}{lcc}
\hline Monomer & $\Delta H_{\mathrm{p}}{ }^{\circ} / \mathrm{KJ} \mathrm{mol}^{-1}$ & $\Delta S_{\mathrm{p}}{ }^{\circ} / \mathrm{J} \mathrm{mol}^{-1} \mathrm{~K}^{-1}$ \\
\hline trans-1 & -23 & -63 \\
Ethylene carbonate & $125.6^{24}$ & - \\
Trimetylene carbonate & $-26^{15}$ & $-44.8^{15}$ \\
\hline
\end{tabular}

We obtained a good linearity, and we estimated $\Delta H_{\mathrm{p}}{ }^{\circ}=-23 \mathrm{~kJ} \mathrm{~mol}^{-1}$ and $\Delta S_{\mathrm{p}}{ }^{\circ}=-63 \mathrm{~J} \mathrm{~K}^{-1} \mathrm{~mol}^{-1}$ from the slope and $y$-intercept, respectively. Table 2 shows the $\Delta H_{\mathrm{p}}{ }^{\circ}$ and $\Delta S_{\mathrm{p}}{ }^{\circ}$ values of the cyclic carbonates, including the values of trans-1. The $\Delta H_{\mathrm{p}}{ }^{\circ}$ of trans-1 showed negative values, which were close to that of trimethylene carbonate; the latter has good ring-opening polymerizability in comparison to the common five-membered cyclic carbonates, such as ethylene carbonate. This indicates that trans-1 has an unusually high ring strain among the five-membered cyclic carbonates. Owing to this high ring strain, trans-1 has a good ring-opening polymerizability, whereas the ring-opening polymerization of cis-1 does not proceed under these conditions.

From the anionic ring-opening polymerization of trans- and cis-1, we conclude that the five-membered cyclic carbonate fused to a six-membered ring in the trans-fashion has sufficient ring-strain to produce the aliphatic polycarbonate without the elimination of $\mathrm{CO}_{2}$ during the polymerization. The good ring-opening polymerizability of MBCG might be due to the trans-fused cyclic carbonate attached to the pyranose ring.

\section{Summary}

The ring-opening polymerizations of trans- and cis-1 were carried out. The ring-opening polymerizations of trans-1 proceeded without the elimination of $\mathrm{CO}_{2}$. The calculation of the thermodynamic parameters of the anionic polymerization of trans-1 gave $\Delta H_{\mathrm{p}}{ }^{\circ}=-23 \mathrm{~kJ} \mathrm{~mol}^{-1}$ and $\Delta S_{\mathrm{p}}^{\circ}=-63 \mathrm{~J} \mathrm{~K}^{-1} \mathrm{~mol}^{-1}$. The negative value of $\Delta H_{\mathrm{p}}{ }^{\circ}$ indicates that trans-1 has a different ring strain in comparison to that of other five-membered cyclic carbonates. 
1 Wang, H., Dong, J. H., Quu, K. Y. \& Gu, Z. W. Synthesis of poly (1,4-dioxan-2-one-cotrimethylene carbonate) for application in drug delivery systems. J. Polym. Sci., Part A: Polym. Chem. 36, 1301-1307 (1998).

2 Zhu, K. J., Hendren, R. W., Jensen, K. \& Pitt, C. G. Synthesis, properties, and biodegradation of poly(1,3-trimethylene carbonate). Macromolecules 24, 1736-1740 (1991).

3 Albertsson, A.-C. \& Eklund, M. J. Influence of molecular structure on the degradation mechanism of degradable polymers: In vitro degradation of poly(trimethylene carbonate), poly(trimethylene carbonate-co-caprolactone), and poly(adipic anhydride). Appl. Polym. Sci. 57, 87-103 (1995).

4 Yokoe, M., Aoi, K. \& Okada, M. Biodegradable polymers based on renewable resources. VII. Novel random and alternating copolycarbonates from 1,4:3,6-dianhydrohexitols and aliphatic diols. J. Polym. Sci., Part A: Polym. Chem. 41, 2312-2321 (2003).

5 Sarel, S. \& Pohoryles, L. A. The stereochemistry and mechanism of reversible polymerization of 2,2-disubstituted 1,3-propanediol carbonates. J. Am. Chem. Soc. 80, 4596-4599 (1958).

6 Kühling, S., Keul, H. \& Höcker, H. Polymers from 2-allyloxymethyl-2-ethyltrimethylene carbonate and copolymers with 2,2-dimethyltrimethylene carbonate obtained by anionic ring-opening polymerization. Makromol. Chem. 191, 1611-1622 (1990).

7 Bialas, N. J., Kühling, S., Keul, H. \& Höcker, H. On the behaviour of benzo-1,3dioxolan-2-one and benzo-1,3-dioxan-2-one versus carbanionic species. Makromol. Chem. 191, 1165-1175 (1990).

8 Kühling, S., Keul, H., Höcker, H., Buysch, H.-J., Schön, N. \& Leitz, E. Polymerization of 5,5-(bicyclo[2.2.1]hept-2-en-5,5-ylidene)-1,3-dioxan-2-one and copolymerization with 5,5-dimethyl-1,3-dioxan-2-one. Macromolecules 24, 4229-4235 (1991).

9 Takata, T., Matsuoka, H. \& Endo, T. Synthesis and Anionic ring-opening polymerization of a novel aromatic cyclic carbonate having binaphthyl structure. Chem. Lett. 2091-2094 (1991).

10 Kühling, S., Keul, H., Höcker, H., Buysch, H.-J. \& Schön, N. Synthesis of poly (2-ethyl-2-hydroxymethyltrimethylene carbonate). Makromol. Chem. 192, 1193-1205 (1991).

11 Takata, T., Kanamaru, M. \& Endo, T. First example of anionic polymerization with azocontaining radical initiators: anionic ring-opening polymerization of cyclic carbonate initiated by azobis(isobutyronitrile) and related azo initiators. Macromolecules 29, 2315-2317 (1996).

12 Takata, T., Matsuoka, H., Hirasa, T., Matsuo, J., Endo, T. \& Furusho, Y. Synthesis and polymerization of cyclic carbonates containing a binaphthyl moiety. Kobunsh Ronbunshu 54, 974-981 (1997).

13 Matsuo, J., Sanda, F. \& Endo, T. Anionic ring-opening polymerization behavior of a seven-membered cyclic carbonate; 1, 3-dioxepan-2-one. J. Polym. Sci., Part A: Polym. Chem. 35, 1375-1380 (1997).

14 Murayama, M., Sanda, F. \& Endo, T. Anionic ring-opening polymerization of a cyclic carbonate having a norbornene structure with amine initiators. Macromolecules 31, 919-923 (1998).

15 Matsuo, J., Aoki, K., Sanda, F. \& Endo, T. Substituent effect on the anionic equilibrium polymerization of six-membered cyclic carbonates. Macromolecules 31, 4432-4438 (1998).
16 Matsuo, J., Sanda, F. \& Endo, T. A novel observation in anionic ring-opening polymerization behavior of cyclic carbonates having aromatic substituents. Macromol. Chem. Phys. 199, 2489-2494 (1998).

17 Shen, Y., Chen, X. \& Gross, R. A. Polycarbonates from Sugars: ring-opening polymerization of 1,2-0-isopropylidene-d-xylofuranose-3,5- cyclic carbonate (IPXTC). Macromolecules 32, 2799-2802 (1999).

18 Takata, T., Murakawa, K. \& Furusho, Y. Synthesis and structure of optically active helical poly- and oligocarbonates consisting of C2-chiral biphenyl unit. Polym. J. 31, 1051-1056 (1999).

19 Sanda, F., Kamatani, J. \& Endo, T. Synthesis and anionic ring-opening polymerization behavior of amino acid-derived cyclic carbonates. Macromolecules 34, 1564-1569 (2001).

20 Carothers, W. J. \& Natta, F. J. V. Studies on polymerization and ring formation. III. Glycol esters of carbonic acid. J. Am. Chem. Soc. 52, 314-326 (1930).

21 Soga, K., Hosoda, S., Tazuke, Y. \& Ikeda, S. Polymerization of propylene carbonate. J. Polym. Sci. Part A: Polym. Chem. 15, 219-229 (1977).

22 Vogdanis, L. \& Heitz, W. Carbon dioxide as a monomer, 3. The polymerization of ethylene carbonate. Macromol. Chem. Rapid Commun. 7, 543-547 (1986).

23 Harris, R. F. J. Structural features of poly(alkylene ether carbonate) diol oligomers by capillary gas chromatography. Appl. Polym. Sci. 37, 183-200 (1989).

24 Vogdanis, L., Martens, B., Uchtmann, H., Hensel, F. \& Heitz, W. Synthetic and thermodynamic investigations in the polymerization of ethylene carbonate. Macromol. Chem. 191, 465-472 (1990).

25 Lee, J.-C. \& Litt, M. H. Ring-opening polymerization of ethylene carbonate and depolymerization of poly(ethylene oxide-co-ethylene carbonate). Macromolecules 33, 1618-1627 (2000)

26 Roebuck, A. \& Adkins, H. trans-1,2-cyclohexanediol. Org. Syntheses Coll. 3, 217 (1955).

27 VanRheenen, V., Kelly, R. C. \& Cha, D. Y. An improved catalytic $\mathrm{OsO}_{4}$ oxidation of olefins to cis-1,2-glycols using tertiary amine oxides as the oxidant. Tetrahedron. Lett. 23, 1973 (1976).

28 Kruper, W. J. \& Dellar, D. V. Catalytic formation of cyclic carbonates from epoxides and $\mathrm{CO}_{2}$ with chromium metalloporphyrinates. J. Org. Chem. 60, 725-727 (1995).

29 Kardouche, N. G. \& Owen, L. N. Dithiols. Part XXVII. Conversion of aliphatic and alicyclic carbonates and thiocarbonates into trithiocarbonates. J. Chem. Soc., Perkins Trans. 754-761 (1975).

30 Beattie, C., North, M., Villuendas, P. \& Young, C. Influence of temperature and pressure on cyclic carbonate synthesis catalyzed by bimetallic aluminum complexes and application to overall syn-bis-hydroxylation of alkenes. J. Org. Chem. 78, 419-426 (2013).

31 Inoue, S., Koinuma, H., Yokoo, Y. \& Tsuruta, T. Stereochemistry of copolymerization of carbon dioxide with epoxycyclohexane. Makromol. Chem. 143, 97-104 (1971).

32 Libiszowski, J., Kowalski, A., Szymanski, R., Duda, A., Raquez, J.-M., Degée, P. \& Dubois, P. Monomer-linear macromolecules-cyclic oligomers equilibria in the polymerization of 1,4-dioxan-2-one. Macromolecules 37, 52-59 (2004). 